\title{
Uso de metodologias ativas sob a ótica de estudantes de graduação em Enfermagem
}

\author{
Karla Taísa Pereira Colares \\ Mestra em Ensino e Saúde pela Universidade Federal dos Vales do Jequitinhonha e Mucuri - UFVJM; \\ Especialização em Metodologia e Inovação do Ensino Superior pela Faculdade Vale do Gorutuba - FAVAG; \\ Especialização em Microbiologia Aplicada pelo Complexo Educacional Ibituruna e Graduada em Biomedicina \\ pela Faculdade de Saúde Ibituruna - FASI. Docente no curso de Enfermagem da FAVAG estudando e aplicando \\ metodologias. Responsável técnica no laboratório de Biologia na Universidade Federal dos Vales do \\ Jequitinhonha e Mucuri, Campus Janaúba \\ $\bowtie$ karla.colares@ufvjm.edu.br \\ Wellington de Oliveira \\ Doutora em Educação pela UFRGS. Membro do Grupo de Estudos de Educação e Relações de Gênero (GEERGE) \\ Professora do Programa de Pós-Graduação em Educação e do Curso de Pedagogia da ULBRA/RS \\ $\triangle$ welltha@terra.com.br
}

Recebido em 12 de janeiro de 2020
Aceito em 15 de setembro de 2020

\begin{abstract}
Resumo:
As discussões acerca dos processos de ensino e aprendizagemna formação profissional emsaúdetêm sido ampliadas, particularmente, sobre o uso das metodologias ativas, tendo em vista as transformações da sociedade contemporânea e uso cada vez mais frequente das tecnologias. 0 objetivo deste estudo é descrever o uso de metodologias ativas no processo formativo de Enfermagem sob a ótica dos estudantes de uma Faculdade Privada, no Norte de Minas Gerais. Trata-se de uma pesquisa exploratória, descritiva e de abordagem quantitativa, na qual os dados foram coletados por meio de umquestionário estruturado, aplicado com auxílio de uma ferramenta online.Responderam ao questionário 111 estudantes que atenderam aos critérios de inclusão e consentiram sua participação por meio do Termo de Consentimento Livre e Esclarecido. A análise e interpretação dos dados foramrealizadas como auxílio do aplicativo de informática Excel 2010 e posterior articulação com a literatura consultada. Os resultados deste estudo revelam uma percepção positiva emrelação ao uso das metodologias ativas no curso de Enfermagem desta Instituição, o que desmistifica a ideia de que os estudantes tenham resistência ao uso de novas estratégias metodológicas. Investir em metodologias que confiram aos estudantes autonomia, criticidade, proatividade; que desenvolvama capacidade de refletir e intervir sobre a realidade, faz-se necessário e urgente. Neste contexto, as metodologias ativas representam potencial para a inovação do Ensino em Saúde.

Palavras-chave: Enfermagem, Ensino em Saúde, Estudante, Metodologias Ativas.
\end{abstract}

\section{Use of active methodologies from the perspective of undergraduate nursing students}

\begin{abstract}
:
Discussions about teaching and learning processes in health professional training have been broadened, particularly on the use of active methodologies, in view of the transformations of contemporary society and the increasingly frequent use of technologies. The objective of this study is to describe the use of active methodologies in the nursing training process from the perspective of students at a Private Faculty, in the North of Minas Gerais. This is an exploratory, descriptive and
\end{abstract}


quantitative research, in which data were collected through a structured questionnaire, applied with the aid of an online tool. 111 students responded to the questionnaire that met the inclusion criteria and consented to their participation through the Informed Consent Form. Data analysis and interpretation were performed with the aid of the Excel 2010 computer application and later articulation with the consulted literature. The results of this study reveal a positive perception regarding the use of active methodologies in the Nursing course at this institution, which demystifies the idea that students are resistant to the use of new methodological strategies. Invest in methodologies that give students autonomy, criticality, proactivity; that develop the capacity to reflect and intervene on reality, it is necessary and urgent. In this context, active methodologies represent a potential for innovation in Health Education.

Keywords: Nursing, Teaching in Health, Student, Active Methodologies.

\section{Uso de metodologías activas desde la perspectiva de estudiantes de licenciatura en enfermería}

\section{Resumen:}

Se han ampliado las discusiones sobre los procesos de enseñanza y aprendizaje en la formación de profesionales de la salud, particularmente sobre el uso de metodologías activas, ante las transformaciones de la sociedad contemporánea y el uso cada vez más frecuente de las tecnologías.El objetivo de este estudio es describir el uso de metodologías activas en el proceso de formación en enfermería desde la perspectiva de estudiantes de una Facultad Privada, en el Norte de Minas Gerais. Se trata de una investigación exploratoria, descriptiva y cuantitativa, en la que se recogieron datos mediante un cuestionario estructurado, aplicado con la ayuda de una herramienta online. 111 estudiantes respondieron al cuestionario que cumplía con los criterios de inclusión y dieron su consentimiento para su participación a través del Formulario de Consentimiento Informado. El análisis e interpretación de los datos se realizó con la ayuda de la aplicación informática Excel 2010 y posterior articulación con la literatura consultada. Los resultados de este estudio revelan una percepción positiva sobre el uso de metodologías activas en el curso de Enfermería de esta institución, lo que desmitifica la idea de que los estudiantes se resisten al uso de nuevas estrategias metodológicas. Invertir en metodologías que le den a los estudiantes autonomía, criticidad, proactividad; que desarrollen la capacidad de reflexionar e intervenir sobre la realidad, es necesario y urgente. En este contexto, las metodologías activas representan un potencial de innovación en Educación para la Salud.

Palabras clave: Enfermería, Enseñanza en Salud, Estudiante, Metodologías Activas.

\section{INTRODUÇÃO}

Diante das transformações na sociedade contemporânea, especialmente, no que tange a evolução da tecnologia e ao volume crescente de informações, as discussões acerca dos processos de ensino e aprendizagem na formação dos profissionais de saúde, têm sido ampliadas (BACICH; MORRAN, 2018). Em um cenário em que o perfil do estudante e a realidade educacional mudaram, há novas expectativas de desempenho para estes profissionais, de modo que o processo formativo deva contemplar o desenvolvimento de habilidades e competências que viabilizem o aprendizado autônomo, crítico-reflexivo e continuado (LIMA FILHO; MARQUES, 2019). 
Sob esta perspectiva as Instituições de Ensino Superior (IES) têm buscado promover mudanças no projeto político pedagógico de seus cursos vislumbrando a formação de profissionais de saúde com competências e habilidades previstas nas Diretrizes Curriculares Nacionais (DCN's) (OLIVEIRA; RODRIGUES; FREITAS, 2018).

As DCN's para o curso de Enfermagem enfatizam a necessidade de se utilizar metodologias de ensino-aprendizagem que estimulem no estudante a autonomia, a criticidade, a capacidade de resolução de impasses em sua realidade e a competência de aprender a aprender. Neste sentido, as metodologias ativas apresentam potencial como estratégia pedagógica no ensino em saúde (BRASIL, 2001; FINI, 2018).

As metodologias ativas referem-se ao um conjunto de estratégias de ensino-aprendizagem que objetivam tornar o aluno protagonista na construção do seu próprio conhecimento. São alguns exemplos de metodologias ativas: Aprendizagem Baseada em Problemas (PBL), Aprendizagem Baseada em Times (TBL), Problematização utilizando o Arco de Mangarez, Sala de aula invertida e Relatos de Experiência (PRADO; TEOTÔNIO, 2020; WEBER, 2018).

Barros et al. (2018) atribuem a relevância do uso das metodologias ativas ao fato do professor deixar de ser o centro do processo de ensino-aprendizagem e o estudante tornar-se responsável e participante, a medida em que ele vai à busca de seu conhecimento, adquirindo aptidões profissionais que provavelmente não conseguiria se estivesse participando de uma forma tradicional de ensino.

Diante do exposto e considerando o perfil do Enfermeiro delineado pelas DCN's, se faz necessário refletir sobre o seu processo formativo, bem como, as metodologias nele envolvidas, investigando, particularmente, sobre a utilização de novas estratégias de ensino aprendizagem. Há a necessidade de conhecer as experiências dos sujeitos que usufruem desses métodos, a fim de se identificar os pontos positivos e negativos com vistas ao aperfeiçoamento.

Considerando a formação acadêmica da pesquisadora e a experiência como docente no curso de Enfermagem, o objetivo deste estudo é descrever o uso de metodologias ativas no processo formativo de Enfermagem sob a ótica dos estudantes de uma Faculdade Privada, no Norte de Minas Gerais. 


\section{METODOLOGIA}

Este estudo trata-se de uma pesquisa exploratória, descritiva e de abordagem quantitativa. Os dados aqui apresentados são parte dos resultados da dissertação intitulada "Perfil de estudantes de Enfermagem e suas percepções sobre o uso de metodologias ativas em seu processo formativo".

O cenário desta pesquisa foi uma faculdade privada, localizada no Norte de Minas Gerais. 0 curso de Enfermagem desta Instituição iniciou-se em 2010, sendo ofertado no período noturno e com duração de dez períodos. Inicialmente a proposta curricular do curso contemplava o ensino tradicional, no entanto, desde 2015 foi adotado o uso prioritário de metodologias ativas em todos os cursos desta Instituição, conforme prevê o Projeto Pedagógico Institucional (PPI). Visando a consolidação deste perfil metodológico e a qualificação dos docentes para a implementação de diferentes metodologias ativas, a Instituição ofereceu aos seus docentes um Curso de Pós-graduação Lato sensu em Metodologia e Inovação no Ensino Superior, com início no segundo semestre de 2015 e conclusão no primeiro semestre de 2017.

O universo amostral foi constituído por estudantes do curso de Enfermagem que atenderam aos critérios de inclusão e se prontificaram em responder ao questionário. Como critério de inclusão adotou-se: ser discente do curso de enfermagem da referida Instituição; possuir idade igual ou superior a 18 anos e não ter participado do teste piloto, conforme recomendado por Marconi e Lakatos (2010). Desse modo, este estudo constituiu-se por uma amostra não probalística, por conveniência. Todos os sujeitos da pesquisa consentiram sua participação através da assinatura do Termo de Consentimento Livre e Esclarecido (TCLE).

Para a coleta de dados utilizou-se um questionário estruturado, adaptado pelo pesquisador a partir de trabalhos semelhantes desenvolvidos por Adada (2017) e Carvalho et al. (2016). O instrumento foi estruturado em três categorias: a primeira, contendo questões a respeito do perfil sociodemográfico do estudante (sexo, idade, estado civil, munícipio de residência, vínculo empregatício, possuir filhos e etc.); a segunda, com questões sobre o perfil escolar e acadêmico (onde concluiu ensino fundamental e médio, período no curso, fontes de estudo extraclasse, locais de estudo extraclasse e etc.) e a terceira, com questões referentes à percepção sobre o uso de metodologias ativas em seu curso (conhecimento sobre as MA's, 
nível de satisfação, grau de aprendizagem e etc.). A maioria das questões foi de múltipla escolha, no entanto, utilizou-se também a escala Likert, de zero a cinco, naquelas em que se desejava mensurar a opinião dos estudantes, a exemplo do nível de satisfação com o uso das MA's.

o questionário foi aplicado nos meses de outubro e novembro de 2018, através de uma ferramenta online. Anteriormente a coleta dos dados, relizou-se o teste piloto em $10 \%$ da população e os indivíduos que participaram do mesmo foram excluídos do universo amostral e, portanto, não constam nos resultados apresentados na secção subsequente (MARCONI E LAKATOS, 2010).

A tabulação e a análise descritiva dos dados foram realizadas com o auxílio do software Excel 2010, a partir do qual foram elaborados gráficos e tabelas. Por fim, foi realizada a articulação entre as informações coletadas e as referências consultadas.

Esta pesquisa respeitou aos preceitos éticos segundo a Resolução do Conselho Nacional de Saúde 466 de 12 de dezembro de 2012, de modo que, seu projeto foi apreciado e aprovado pelo Comitê de Ética em Pesquisa da UFVJM, sob o parecer de Número 2.827.560. Aos discentes respondentes foi assegurado o anonimato, a privacidade e voluntariedade.

\section{RESULTADOS E DISCUSSÃo}

No segundo semestre de 2018 haviam 235 estudantes matriculados no curso de Enfermagem da Instituição pesquisada, destes $111(47,2 \%)$ responderam ao questionário. Quanto às características dos entrevistados, a maioria 95 (85,6\%) é do sexo feminino, com idade entre 18 e 27 anos 83 (74,7\%), solteiros 76 (68,5\%), com renda familiar de até três salários mínimos 84 (75,6\%), 107 (96,4\%) concluíram o Ensino Médio em Escola Pública e 79 (71,2\%) declararam trabalhar além de estudar.

Ao investigar se os estudantes compreendiam basicamente o conceito de metodologia ativa, a maioria $106(95,5 \%)$ selecionou a opção "Atividades em que os alunos participam da aula (questionando, pesquisando e etc.)", demonstrando assim, que os mesmos compreendem o princípio elementar desta metodologia que é a participação ativa do estudante. 
Diferindo-se dos resultados deste estudo Adada (2017) identificou em sua pesquisa que $89 \%$ dos estudantes não conheciam esta nova abordagem pedagógica. Tal divergência com os achados deste estudo sugere a existência de um diálogo entre corpo docente e discente a respeito das estratégias de ensino utilizadas no curso de Enfermagem. Souza et al. (2018) ao investigarem esta variável junto a estudantes de Enfermagem de uma Instituição de Icó (CE), também observaram que os discentes apresentavam pouco conhecimento em relação as metodologias ativas, porém, mesmo desconhecendo esses métodos a maioria dos pesquisados declarou preferir aulas mais interativas, com enfoque na troca de conhecimentos entre professores e alunos, o que é algo característico das metodologias inovadoras.

Todos os pesquisados afirmaram que seus professores já utilizaram metodologias ativas em algum momento do curso. Tal resultado corrobora a proposta pedagógica da Instituição de uso prioritário de metodologias inovadoras em seus cursos. Cabe ressaltar, que o enunciado desta questão continha exemplos do que seriam aulas com metodologias ativas, o que pode ter esclarecido o seu conceito para aqueles estudantes que na questão anterior não o compreendiam.

No que concerne à experiência prévia com metodologias ativas, mais da metade dos pesquisados $57(51,4 \%)$ declarou nunca tê-las vivenciado antes da graduação, assemelhandose ao encontrado por Carvalho et al. (2016) ao pesquisarem a aceitação da utilização dessas metodologias por discentes da graduação e pós-graduação em Odontologia. Estes resultados demonstram que a metodologia tradicional é ainda, predominantemente empregada na grande maioria das escolas de ensino fundamental e médio brasileiras. Por outro lado, percebe-se que a familiaridade dos estudantes de graduação com as metodologias ativas vem sendo ampliada.

Conforme pode se observar no Gráfico 1, a maioria dos acadêmicos 102 (91,9\%) afirmou aprender melhor com aulas/ atividades que utilizam metodologias ativas, demonstrando uma boa aceitação desta estratégia metodológica. Ao serem solicitados a estimar, a partir de escala Likert, o grau de aprendizagem com metodologias ativas, a maioria dos estudantes $99(89,2 \%)$ avaliou entre quatro e cinco seu nível de aprendizagem, corroborando o resultado anterior. Já com relação à metodologia tradicional, a maioria 81 (73,0\%) mensurou um nível de aprendizagem entre um e três (Gráfico 2). 
Gráfico 1 - Metodologia com que os estudantes de Enfermagem consideram aprender melhor

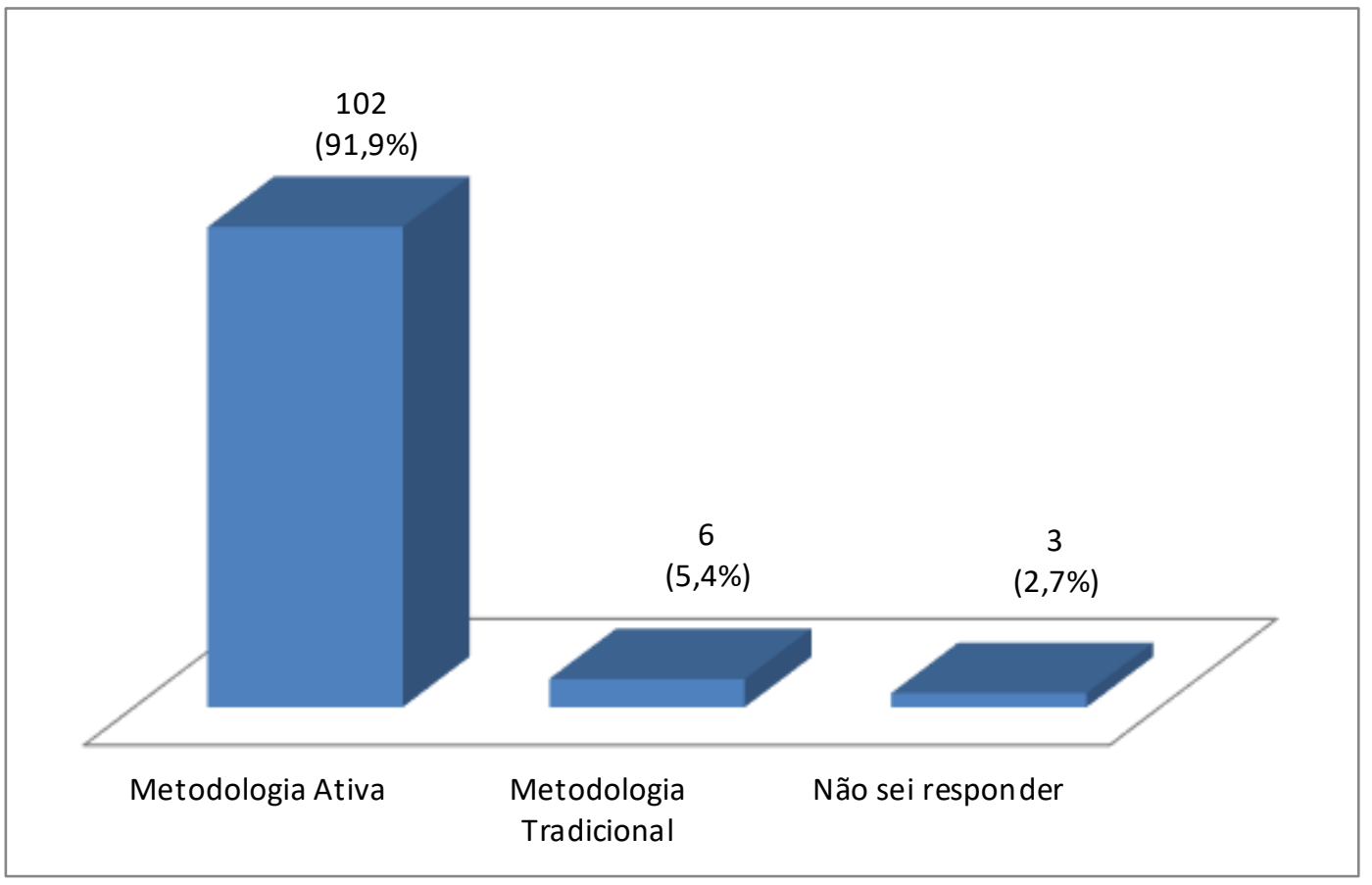

Fonte: Elaborado pelo autor, 2019.

Gráfico 2 - Estimativa dos estudantes de Enfermagem com relação do grau de aprendizagem que consideram apresentar nas aulas com Metodologia Ativa e Tradicional

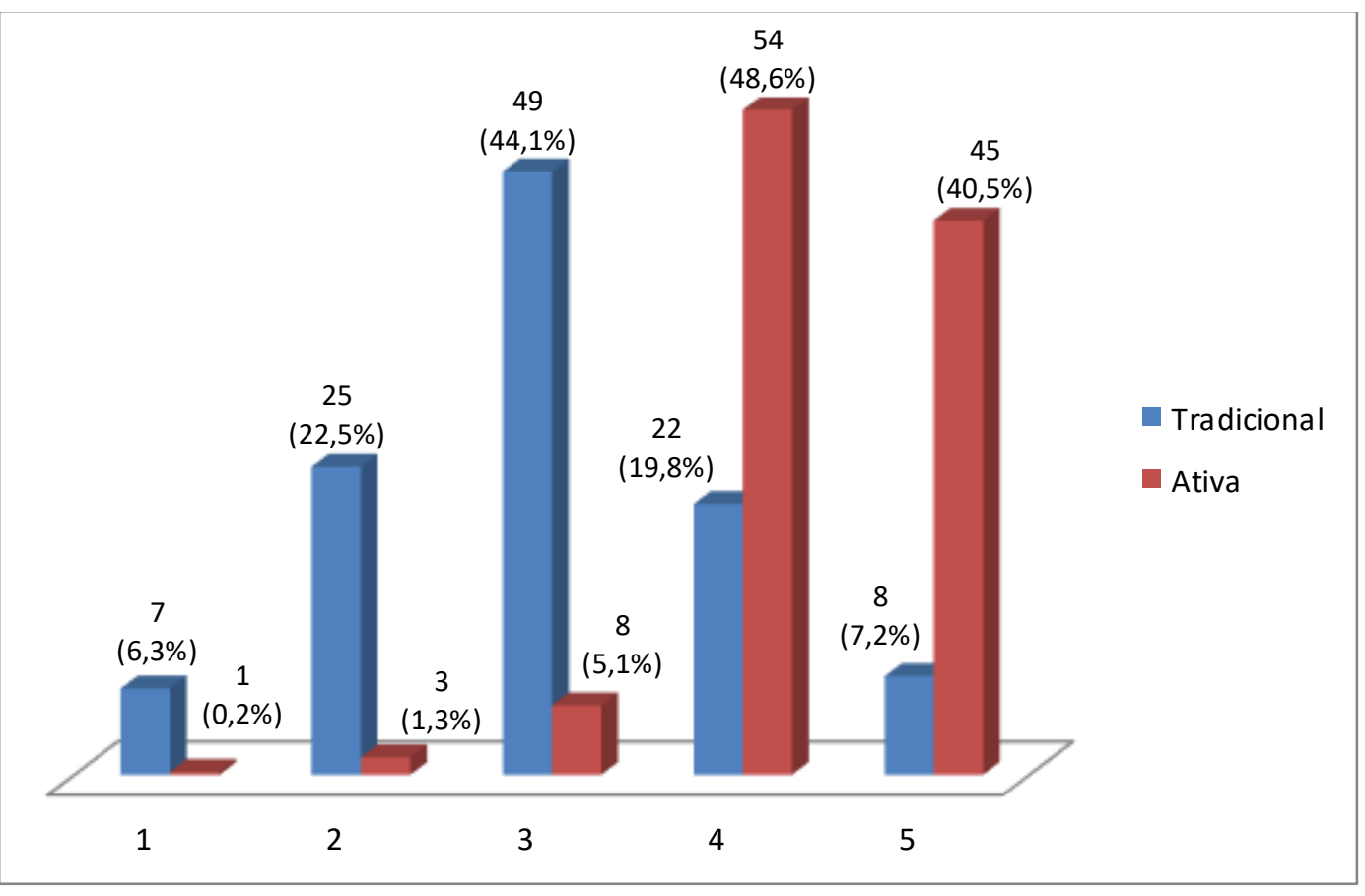

Fonte: Elaborado pelo autor, 2019. 
Os resultados acima descritos demonstram uma boa receptividade dos estudantes às metodologias inovadoras. Mendes et al. (2017) em seu estudo com discentes de administração identificaram que $43,3 \%$ dos alunos aprovam totalmente as metodologias ativas, 53,4\% aprovam parcialmente, enquanto $3,3 \%$ dos alunos reprovam parcialmente, de modo que nenhum dos alunos foi indiferente ou reprovou totalmente a nova metodologia de ensino.

Carvalho et al. (2016) demonstraram a satisfação dos alunos com o método da PBL, refutando a ideia de dificuldade de aceitação a novas metodologias. Os autores acrescentam que os acadêmicos valorizaram a oportunidade de compartilhar suas experiências e conhecimentos e sentiram se mais motivados ao terem suas opiniões consideradas durante as aulas.

Xavier et al. (2016) também revelaram uma percepção positiva dos discentes de um Programa de Pós-Graduação Strictu sensu da Universidade Estadual de Montes Claros quanto ao método PBL e sua eficácia na disciplina em que foi aplicado.

A partir da Tabela 1 pode se observar que a maioria dos estudantes 81 (73,0\%) afirmou não apresentar mais dificuldade durante as aulas que utilizam metodologias ativas quando comparadas às aulas tradicionais. No entanto, 18 acadêmicos (16,2\%) relataram apresentar mais dificuldades com as metodologias inovadoras, e desses 10 (55,6\%) mensuraram em três seu nível de dificuldade, a partir de Escala Likert de um a cinco, na qual cinco refere-se ao grau máximo de dificuldade.

Quanto ao tipo de dificuldade que consideram apresentar, os estudantes poderiam optar por mais de uma resposta o que resultou em 25 citações, dentre as quais, compreender a atividade proposta, organizar ideias e apresentar trabalhos foram as limitações mais apontadas. 
Tabela 1 - Avaliação dos estudantes de Enfermagem sobre dificuldade em aulas que utilizam metodologias ativas quando comparadas a aulas com metodologia tradicional

\begin{tabular}{lcr}
\hline & Variável & \% \\
\hline Considera sentir mais dificuldade em aulas com MA's do que com Tradicionais \\
Não & 81 & 73,0 \\
Sim & 18 & 16,2 \\
Não sei responder & 12 & 10,8 \\
Total & 111 & $100 \%$
\end{tabular}

Nível de dificuldade atribuído, em escala Likert de 1 a 5

2

3

$10 \quad 55,6$

4

$4 \quad 22,2$

5

$1 \quad 5,6$

Total

$18 \quad 100 \%$

Tipo de dificuldade que considera apresentar ao utilizar MA's

$\begin{array}{lll}\text { Compreender a atividade proposta } & 6 & 24,0\end{array}$

$\begin{array}{lrr}\text { Organizar ideias } & 5 & 20,0\end{array}$

$\begin{array}{lrr}\text { Apresentar trabalhos } & 5 & 20,0\end{array}$

Compreender como funcionam as metodologias ativas $\begin{array}{lll}3 & 12,0\end{array}$

$\begin{array}{lrr}\text { Trabalhar em equipe } & 3 & 12,0\end{array}$

$\begin{array}{lll}\text { Agir de forma mais independente do professor } & 2 & 8,0\end{array}$

Argumentar quando um colega ou professor lhe faz alguma

pergunta $\quad \begin{array}{rr}1 & 4,0\end{array}$

$\begin{array}{lll}\text { Total } & 25 & 100 \%\end{array}$

A quantidade de citações é superior à quantidade de respostas devido à possibilidade de repostas múltiplas (máximo de nove respostas).

Fonte: Elaborado pelo autor, 2019. 
Ao investigarem os pontos negativos do PBL Xavier et al. (2016) identificaram a partir dos relatos dos estudantes, o maior tempo requerido para os estudos, a independência em relação ao professor e a pressão pela participação dos estudantes mais tímidos.

Sugere-se que os resultados encontrados neste estudo possam refletir a ausência ou insuficiência de estudo prévio, o qual constitui etapa fundamental para o êxito de diferentes estratégias de metodologias inovadoras, a exemplo da sala de aula invertida.

Com relação à dificuldade em apresentar trabalhos pode se pressupor que a timidez ou a falta de habilidades comunicacionais representem um obstáculo na execução de tal atividade. No entanto, é importante considerar que a habilidade de comunicação é componente essencial para o cuidado de enfermagem e que pode ser desenvolvida a partir de diferentes estratégias a exemplo, da simulação conforme mencionado por Carvalho (2011).

Oliveira e Braga (2016) ratificam que é fundamental a construção de habilidades comunicativas, desde o início da formação acadêmica, na qual o graduando de enfermagem compreenda a importância do relacionamento interpessoal e do uso adequado da comunicação no contexto do cuidado, para que possa estabelecer relacionamentos efetivos e significativos em sua atividade profissional.

Conforme salientado por Lopes et al. (2017) nem todos os estudantes se adequam as metodologias ativas da mesma maneira, gerando com isso a necessidade de se mapear quais são os principais pontos negativos nas experiências com estas metodologias. Neste sentido, ressalta-se que bons resultados, com qualquer metodologia, requer conhecer as suas fragilidades e potencialidades tanto sob a ótica do discente quanto do docente.

Ao serem interrogados se consideram que as metodologias ativas oportunizam relacionar o conhecimento entre as diferentes disciplinas, 86 (77,5\%) acadêmicos declararam "sim, bastante", 23 (20,7\%) "sim, um pouco" e dois (1,8\%) "sim, muito pouco". Diante destes resultados, percebe-se que todos os discentes consideram a possibilidade de integrar o conhecimento de maneira interdisciplinar a partir das metodologias inovadoras, ainda que em diferentes intensidades.

Santos et al. (2017) afirmam que a abordagem interdisciplinar de temas convergentes é relevante tanto na teoria quanto na prática e estimula a articulação dos múltiplos saberes. 
Acrescentam que a fragmentação dos cursos em disciplinas, na maioria das vezes, ministradas de maneira isolada, ainda é uma problemática no Ensino Superior, e estimulam os docentes a valorizarem os trabalhos com metodologias ativas, especialmente em grupo, em todos os anos da graduação.

Ainda de acordo com Santos et al. (2017), promover o diálogo entre disciplinas pode influenciar a percepção do aluno quanto à importância de cada uma em seu processo de aprendizagem. Além disso, por meio das atividades interdisciplinares, os alunos se sentem mais motivados para o estudo e compreendem melhor os assuntos abordados em sua complexidade.

Corroborando Paranhos e Mendes (2010) afirmam que o currículo integrado e orientado por competência, requer instrumentar professores e estudantes para a utilização de metodologia ativa, no sentido de estar articulada e compromissada com a resolutividade nas situações de cuidado em saúde. Assim, investir na formação de profissionais que busquem desenvolver uma prática orientada às necessidades de saúde da população e ao exercício da autonomia, aliado ao raciocínio investigativo, criatividade, capacidade de comunicação e de resolução de problemas, em que se apropria o trabalho em equipe interdisciplinar, centrado no ser humano e a profissão, se faz necessário e urgente.

Com relação a considerarem se as metodologias ativas possibilitam a correlação com os conhecimentos prévios 82 (73,9\%) acadêmicos afirmaram "sim bastante", 26 (23,4\%) "sim um pouco", dois $(1,8 \%)$ "sim, muito pouco" e apenas um $(0,9 \%)$ não considera a possibilidade da correlação.

A teoria da aprendizagem significativa de Ausubel (1982) defende que a incorporação de novos conhecimentos de maneira significativa ocorre a partir dos conhecimentos prévios que o estudante traz consigo. Ele afirma ainda, que se o conteúdo não for significativo para o aluno, ele o armazenará de maneira isolada, podendo esquecê-lo em seguida. Neste caso ocorre apenas a aprendizagem mecânica fundamentada meramente na memorização de conteúdos.

A teoria de Ausubel dialoga com o educador contemporâneo Paulo Freire (1996) o qual propõe que nenhum indivíduo deve ser tratado como um recipiente vazio, de modo que, o conhecimento prévio deve ser respeitado e explorado no processo de ensino aprendizagem. 
Diante do exposto, entende-se que dispor de um caminho metodológico que valorize experiências prévias dos estudantes constitui premissa fundamental na formação profissional em saúde. A luz dos resultados acima apresentados nota-se na percepção, da maioria dos discentes, que as metodologias ativas favorecem a articulação entre o conhecimento prévio e o novo conhecimento adquirido.

Evidenciou-se em um total de 106 (95,5\%) (considerando os indicadores "sim, bastante", "sim, um pouco" e "sim muito pouco") pesquisados que a organização dos conteúdos na proposta das metodologias ativas, facilitou a aprendizagem e compreensão.

Diesel, Baldez e Martins (2017) dizem que no contexto da sala de aula, o docente deve problematizar os conteúdos com o intuito de instigar uma análise sobre a realidade e a tomada de consciência sobre ela. Para isso faz-se necessário que o professor conheça as situações e os problemas aos quais o conteúdo esta ligado, objetivando suscitar no estudante o desejo de aprender. Destacam que, muitas vezes, reside aí uma dificuldade, pois nem sempre o docente consegue atender a esse requisito.

Sob este ponto de vista, a fragmentação dos conteúdos e sua desarticulação com o contexto social pode ser uma das causas de desmotivação e desinteresse dos estudantes. Daí a importância de que a educação desenvolvida nos ambientes formais de ensino precisa ser útil para a vida, viabilizando articular o conhecimento construído com possibilidades reais de sua aplicação prática, ou seja, aprender com sentido, com significado contextualizado (DIESEL; BALDEZ; MARTINS, 2017).

Investigar o engajamento dos estudantes pode trazer importantes contribuições para o desenvolvimento do projeto de curso assim como o institucional, pois influencia nos resultados dos estudantes em relação à aprendizagem e persistência.

As respostas referentes ao nível de engajamento dos estudantes no processo de ensino-aprendizagem que utiliza metodologias ativas encontram-se representadas no gráfico 3. Nota-se que o nível de engajamento proporcionado é positivo, uma vez que, 81 (73,0\%) acadêmicos avaliaram entre excelente e ótimo. 
Gráfico 3 - Nível de engajamento que os estudantes de Enfermagem consideram apresentar no processo de ensino-aprendizagem que utiliza metodologias ativas

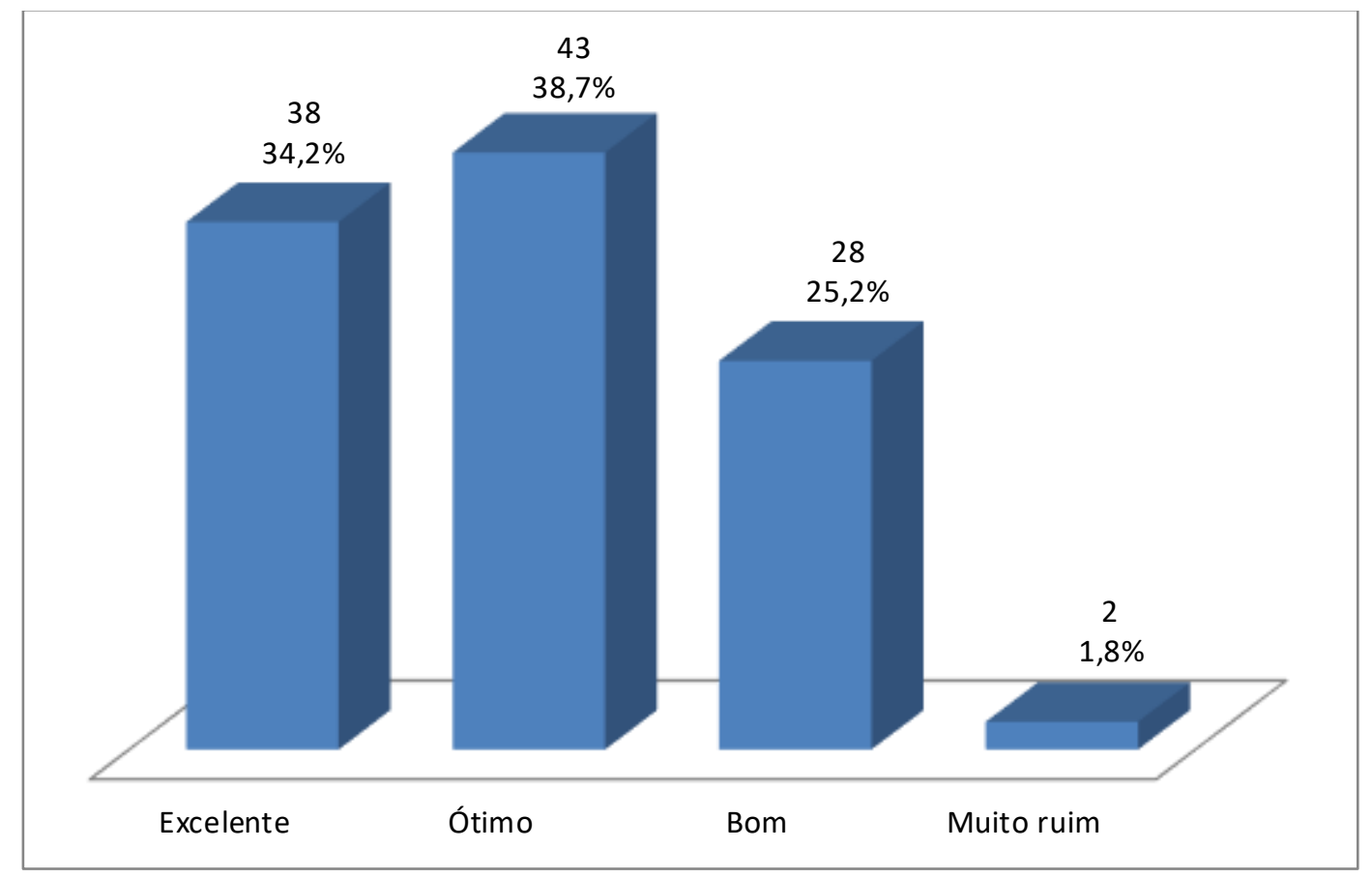

Fonte: Elaborado pelo autor, 2019.

O engajamento é um fator já estudado e avaliado internacionalmente, e tem sido utilizado como um indicador para avaliar a qualidade de oferta no ensino. Silva et al. (2018) afirmam que o engajamento pode ser percebido no indivíduo pela energia despendida, pelo envolvimento e pela eficácia ao desempenhar determinada atividade.

Ainda de acordo com Silva et al. (2018), quando utilizado com estudantes de Ensino Superior, o conceito de engajamento exibe as mesmas características. Estudantes engajados se sentem vinculados às suas atividades e as percebem como um desafio positivo. As pessoas engajadas mostram-se abertas a novas experiências, sendo capazes de explorar com avidez o ambiente/situação em que se encontram, tornando-se inclusive mais criativas.

Martins e Ribeiro (2017) corroboram ao atestar que o engajamento auxilia professores e estudantes a se envolverem ativamente em experiências de aprendizagem, podendo ser visto como uma parceira que envolve alunos, professores e instituição de ensino para promover aprendizagem de qualidade.

Os autores supracitados acrescentam que o currículo do curso, intencionalmente elaborado, pode impactar o engajamento do estudante motivando-os a aprender, 
promovendo um clima positivo e encorajando os estudantes a serem ativos em sua aprendizagem.

Vitória et al. (2018) apontam que o engajamento acadêmico envolve três dimensões fundamentais: a comportamental; a afetiva; e a cognitiva. O nível comportamental se relaciona à participação, às iniciativas dos alunos diante de uma atividade, à assiduidade e à capacidade de observar e respeitar normas estabelecidas em sala de aula. O nível afetivo está associado aos interesses, valores e emoções, como: identificação com o estilo de uma atividade, ansiedade, tédio ou felicidade. Essa dimensão envolve, pois, os aspectos subjetivos dos estudantes e que são os desencadeadores de toda e qualquer ação, sobretudo no que se refere às ações e aos processos educativos. Por fim, no nível cognitivo situam-se os investimentos pessoais, esforços e disposições que se destinam à aprendizagem e ao domínio do conhecimento. Contudo, os autores destacam que, para que ocorra um engajamento efetivo dos estudantes, essas três dimensões devem atuar de forma sinérgica e ser mobilizadas nos discentes em mesmo grau de intensidade e relevância, pois a dimensão afetiva, apesar de ser o elemento propulsor da ação, não possibilita o engajamento acadêmico sem a dimensão cognitiva (o trabalho intelectual) e a dimensão comportamental (as ações, as atitudes).

Outro aspecto de grande relevância no que tange ao processo de ensino aprendizagem refere-se à relação entre docentes e discentes. Ramos (2011, p.181) afirma que "nenhum avanço tecnológico poderá substituir o calor das relações humanas estabelecidas fraternalmente, sendo o professor e a construção de sua ligação com o educando o centro de qualquer prática pedagógica".

Considerando a docência uma atividade que exige dos professores conhecimentos teóricos, práticos, atitudes e vivências que podem influenciar e contribuir na formação em enfermagem, indagou se aos estudantes se eles consideram que as metodologias ativas facilitam a interação professor/aluno, mais do que as metodologias tradicionais. As respostas dos estudantes estão representadas na Tabela 2. Conforme pode se observar quase a totalidade dos estudantes $110(99,1 \%)$ consideram que as metodologias inovadoras favorecem a relação interpessoal entre discentes e docentes, sendo que apenas um $(0,9 \%)$ acadêmico afirma não haver contribuição. Ainda sob a perspectiva dessa relação interpessoal, todos os pesquisados declararam que a interação professor/aluno, estabelecida nas metodologias 
ativas, favorece o processo de ensino aprendizagem, havendo opiniões distintas apenas com relação à intensidade dessa contribuição.

Tabela 2 - Relação professor/ aluno nas MA's, sob a percepção dos estudantes de Enfermagem

\begin{tabular}{lcc}
\hline Variável & N & \% \\
$\begin{array}{l}\text { Considerar que as MA's facilitam a interação professor } \\
\text { metodoluno, mais do que na } \\
\text { Sim, bastante }\end{array}$ & 91 & 82,0 \\
Sim, um pouco & 17 & 15,3 \\
Sim, muito pouco & 2 & 1,8 \\
Não & 1 & 0,9 \\
Total & 111 & $100 \%$ \\
A relação estabelecida entre professor/ aluno, durante & as aulas com MA's favorece o \\
processo de ensino aprendizagem? & & 82,9 \\
Sim, bastante & 92 & 12,6 \\
Sim, um pouco & 14 & 4,5 \\
Sim, muito pouco & 5 & $100 \%$ \\
Total & 111 & \\
\hline Fonte: Elaborado pelo autor, 2019. & &
\end{tabular}

De acordo com Silva (2016) o processo de ensino-aprendizagem na enfermagem, em grande parte, está alicerçado na relação entre teoria e prática, seja na academia ou nos serviços de saúde. A atuação docente constitui componente essencial na integração de conhecimentos na enfermagem, provendo o apoio necessário para o desenvolvimento profissional. Neste contexto, os docentes não somente instruem, mas também motivam os discentes nas tomadas de decisões, no desenvolvimento de habilidades e atitudes que visam à aquisição de conhecimentos técnicos, sociais e políticos em prol da sociedade. A prática docente, portanto, refere-se a uma atividade social complexa que combina diferentes fazeres, conhecimentos, atitudes, expectativas, ações e estratégias, de acordo com sua visão de mundo. 
No que concerne às estratégias pedagógicas desenvolvidas com os futuros profissionais da saúde, que lidam diretamente com seres humanos em momentos decisivos de vida, muitas vezes, envolvendo risco iminente de morte, faz-se necessário que as relações estabelecidas no ambiente acadêmico sejam convergentes com valores que priorizem a humanização em saúde, a fim de que a postura adotada seja replicada com a população que será assistida. Neste sentido, a relação docente-discente pode propiciar o entendimento e desenvolvimento das interações acerca do viver em sociedade que exprimem os modos comportamentais positivos como solidariedade, lealdade, respeito, ética, responsabilidade, entre outros, assim como o contrário também pode ser verdadeiro (SANTANA et al., 2015).

Para Santos e Soares (2011) a interação professor-aluno, saudável, complementar e dialógica, só é possível quando o professor investe em uma aprendizagem significativa, buscando todos os meios de conquistar o estudante para o desafiante processo de se abrir para o novo, de ressignificar as marcas da passividade e da memorização, de construir conhecimentos e atitudes de forma ativa e autônoma.

O professor, permeado por uma boa prática social e didática, deve ser consciente que é necessário estabelecer relações positivas para atingir os objetivos de ensino aprendizagem, provendo a ruptura da verticalidade da relação entre docentes e discentes. Freire (1996) afirma ser necessário aos envolvidos no processo de formação universitária possuir o entendimento de que não há docência sem discência, pois quem ensina aprende ao ensinar e quem aprende ensina ao aprender.

Ao investigar como os pesquisados consideram o papel do professor na abordagem das metodologias ativas, verificou-se que 100 (90,1\%) estudantes consideram o docente como "mediador/ orientador - Dialogando de forma mais próxima sobre os conteúdos e orientando os alunos na forma como aprender e fixar os conteúdos".

Para Adada (2017) a compreensão que trazemos do processo de ensino e aprendizagem sob a abordagem das metodologias ativas, provoca alterações significativas no papel e na atuação do aluno, assim como do professor, exigindo de ambos participação, envolvimento, pesquisa, entre outras práticas.

Ao serem indagados se consideram seus professores preparados para trabalhar com as metodologias inovadoras, nota-se que a maioria dos estudantes $97(87,4 \%)$ reconhece que 
há o preparo dos docentes, ao considerarmos os indicadores "sim, bastante" e "sim, um pouco". No entanto, evidencia-se a necessidade do aprimoramento. Adada (2017) corrobora estes resultados e afirma que é natural que surjam algumas lacunas diante de uma abordagem tão ampla e tão abrangente como a das metodologias ativas. Acrescenta-se que por se tratar de uma metodologia recentemente implantada na Instituição de Ensino pesquisada, possa haver ainda, dificuldades na compreensão e aplicação dessas estratégias metodológicas por parte dos docentes.

Não obstante, Macedo et al. (2018) destacam que a qualificação docente sobre as metodologias inovadoras de aprendizagem é potencial para a transformação de práticas e para a inovação no ensino em saúde.

A formação de profissionais de saúde críticos, reflexivos e transformadores de suas realidades está intimamente ligada às concepções pedagógicas que estimulam o aprender a aprender. Sendo assim, a discussão e a vivência dessas metodologias pode se tornar importante estratégia para a instrumentalização e a atuação por parte desses docentes (MACEDO et al., 2018).

No que tange ao nível de realização pessoal em atividades relacionadas às metodologias ativas, observou-se um nível de satisfação positivo pelos estudantes 101 (91\%), sendo que $29(26,1 \%)$ estão muito satisfeitos e $72(64,9 \%)$ consideram-se satisfeitos com a utilização destas metodologias em seu curso. De modo semelhante, Adada (2017) também identificou uma satisfação positiva em relação ao uso das metodologias inovadoras 52 (82,5\%), sendo que nove $(14,3 \%)$ acadêmicos relataram estar muito satisfeitos e 43 (68,2\%) satisfeitos.

Christofoletti et al. (2014), ao pesquisarem o grau de satisfação discentes frente à utilização de métodos ativos de aprendizagem em uma disciplina de Ética em Saúde, também revelaram uma experiência positiva, sendo que $89,2 \%$ dos estudantes afirmaram estar satisfeitos com o uso deste método.

Ainda, em conformidade com os resultados deste estudo, Marin et al. (2010) também evidenciaram uma avaliação positiva do uso das metodologias ativas em cursos de pós graduação multiprofissional em saúde. Os autores mencionam que os egressos apontaram haver uma ampliação e contextualização da realidade, viabilizando a articulação entre teoria 
e prática, e ainda, o desenvolvimento da capacidade de conviver, de trabalhar em equipe e o respeito aos diferentes saberes, necessários ao cuidado integral à saúde.

Quanto à possibilidade de utilizarem futuramente, em seu exercício profissional, estratégias de metodologias ativas, 108 (97,3\%) estudantes responderam "sim", corroborando assim, a satisfação em relação ao uso dessas metodologias.

Ao pesquisar esta mesma variável junto a estudantes de um Programa de mestrado em Odontologia, Carvalho et al. (2016) identificaram que todos os pesquisados mostraram uma percepção positiva, havendo unanimidade sobre a relevância de sua utilização no exercício profissional futuro.

Diante dos dados aqui apresentados, acredita-se que o conhecer a percepção dos estudantes em relação às metodologias utilizadas em seu processo formativo, é essencial para o desenvolvimento e aprimoramento de estratégias pedagógicas mais adequadas e exitosas. Deste modo, sugere-se que o conjunto de dados aqui apresentados possam subsidiar reflexões e decisões institucionais, especialmente, no que concerne à capacitação dos docentes para a utilização de estratégias de ensino-aprendizagem mais adequadas ao perfil e condições dos estudantes. Salienta-se ainda, a relevância da capacitação docente permanente fundamentada nos princípios das DCN's vislumbrando a formação de um profissional crítico e reflexivo, apto a atuar conforme as necessidades dos serviços de saúde e da população.

\section{CONSIDERAÇÕES FINAIS}

Os resultados deste estudo revelam uma percepção positiva em relação ao uso das metodologias ativas no curso de Enfermagem, o que desmistifica a ideia de que os estudantes tenham resistência ao uso de novas estratégias metodológicas. Para determinar que houve uma avaliação positiva foi observado o escore elevado nas variáveis: grau de aprendizagem, engajamento, relação professor/aluno e nível de realização pessoal.

É possível sugerir que o conjunto de informações aqui apresentado possa contribuir para o aprimoramento da atuação docente assim como, suscitar reflexões que norteiam a prática pedagógica e o ensino em saúde. 
Como limitações deste estudo pode-se mencionar a dificuldade em generalizar estes resultados para outras realidades, uma vez que, a pesquisa foi realizada em apenas uma Instituição de Ensino Superior. Mesmo assim, estes resultados possibilitam a compreensão da percepção dos estudantes sobre o uso das metodologias ativas, demonstrando suas potencialidades e apontando para a necessidade de se continuar a investigar esta prática de ensino, objetivando aperfeiçoá-la e ajustá-la às necessidades dos estudantes e às demandas da sociedade contemporânea, bem como, desenvolver instrumentos que facilitem a avaliação e monitorização do impacto das mudanças introduzidas. Para a complementariedade destes achados sugere-se ainda, a realização de uma investigação de cunho qualitativo a fim de apresentar as percepções não reveladas pela análise quantitativa.

\section{REFERÊNCIAS}

ADADA, Flávia. Estudo sobre a percepção do discente sobre as metodologias ati vas na educação superior. 2017. 142 f. Dissertação (Mestrado em Educação) - Universidade Estadual do Oeste do Paraná, UNIOESTE. Cascável.2017. 130f. Disponível em: http://tede.unioeste.br/handle/tede/3340. Acesso em: 23 de setembro de 2018.

AUSUBEL, D. P. A aprendizagem significativa: a teoria de David Ausubel. São Paulo:Moraes, 1982.

BACICH, L.; MORRAN, J. Metodologias Ati vas para uma Educação Inovadora: Uma Abordagem Teórico-Prática. Porto Alegre: Penso, 2018. Disponível em:

<https://books.google.com.br/books?id=TTY7DwAAQBAJ\&pg=PT4\&source=kp_read_button\&redir_esc=y\#v=onepag e\&q\&f=false>. Acesso em: 14 de agosto de 2019.

BARROS, F. F.; GUEDES, J;; ZERB INATTI, L. F.; RIBEIRO, E. R. Emprego de metodologias ativas na área da saúde nos últimos cinco anos: revisão integrativa. Revista Espaço para a Saúde, Londrina, v. 19, n. 2, p.108-119, dez. 2018. Disponível em:

https://www.researchgate.net/publication/329893471_Emprego_de_metodologias_ativas_na_area_da_saude_nos_ ultimos_cinco_anos_revisao_integrativa> . Acesso em: 05 de maio de 2019.

BRASIL. Ministério da Educação. Conselho Nacional de Educação. Resolução no 3 de 7 de novembro de 2001. Diretrizes Curriculares Nacionais do Curso de Graduação em Enfermagem. Disponível em: $<$ http://portal.mec.gov.br/cne/arquivos/pdf/CES03.pdf>. Acesso em: 05 de julho de 2018.

CARVALHO, E. M. Desenvolvendo habilidades e competências para a comunicação com o paciente. REME - Revi sta Mineira de Enfermagem; Belo Horizonte, v.15, n. 3, p.311,jan/mar, 2011. Disponível em:< http://www.reme.org.br/artigo/detalhes/39>. Acesso em: 10 de dezembro de 2018.

CARVALHO, W. M; CAWHISA, P. T; SCHEIBEL, P. C; BOTELHO, J. N; TERADA, R. S. S; ROCHA, N. B; LOLLI, L. F; FUJIMAKI, M. Aceitação da utilização de metodologias ativas nos estágios no SUS por discentes da graduação e pósgraduação em Odontologia. Revista da ABENO, v. 16, n. 1, p. 88-98, 2016. Disponível em: <https://revabeno.emnuvens.com.br/revabeno/article/view/224>. Acesso em: 06 de janeirode 2019.

CHRISTOFOLETTI, G; FERNANDES, J. M; MARTINS, A. S; OLIVEIRA JUNIOR, S. A; CARREGARO, R. L; TOLEDO, A. M. Grau de satisfação discente frente à utilização de métodos ativos de aprendizagem em uma disciplina de Ética em saúde. Revista Eletrônica de Educação, São Carlos, v. 8, n. 2, p. 188-197, 2014. Disponível em:

<http://www.reveduc.ufscar.br/index.php/reveduc/article/view/823/334 >. Acesso em: 15 de fevereiro de 2019. 
DIESEL, A; BALDEZ, A. L. S; MARTINS, S. N. Os princípios das metodologias ativas de ensino: uma abordagem teórica. Revista Thema, Lajeado, v. 14, n.1, p. 268-288, 2017. Disponível em: <

http://revistathema.ifsul.edu.br/index.php/thema/article/view/404>. Acesso em: 03 de julho de 2018.

FINI, M. I. Inovações no ensino superior metodologias inovadoras de aprendizagem e suas relações com o mundo do trabalho: desafios para a transformação de uma cultura. Admi nistração: Ensi no e Pesqui sa, Rio de Janeiro, v. 19, p.176-183,jan./abr. 2018. Disponível em: < https://raep.emnuvens.com.br/raep/article/view/982>. Acesso em $02 \mathrm{de}$ janeiro de 2019.

FREIRE, P. Pedagogi a da autonomia: saberes necessári os à prática educativa. 11. Ed. Rio de Janeiro: Paz e Terra, 1996.

LIMA FILHO, P. R. S; MARQUES, R.V.D. A. Perspectivas sobre o Aprendizado na Óptica de Estudantes de Medicina: Análise do Impacto de Transição Curricular. Revista brasi leira de educação médi ca, B rasília, v. 43, n. 2, p. 87-94, jun. 2019. Disponível em: http://www.scielo.br/scielo.php?script=sci_arttext\&pid=S0100$55022019000200087 \& \operatorname{lng}=$ pt\&nrm=iso. Acesso em: 18 de agosto de 2020.

LOPES, T. T. V; CARNUT, L; GUERRA, L. D. S; ZILBOVICIUS, C; PEREIRA, A. L. P. Pontos negativos na visão dos residentes sobre a aprendizagem dos conteúdos antropológicos e sociais a partir do uso de metodologias ativas de ensino-aprendizagem. Journal of Management \& Primary Health Care. v. 8, n. 3, p. 89-90, 2017. Disponível em: <http://jmphc.com.br/jmphc/article/view/685>. Acesso em: 10 de fevereiro de 2019.

MACEDO, K. D. S; ACOSTA, B. S; SILVA, E. B; SOUZA, N. S; BECK, C. L.C; SILVA, K. K.D. Metodologias ativas de aprendizagem: caminhos possíveis para inovação no ensino em saúde. Escola Anna Nery, Rio de Janeiro, v. 22, n. 3, p. 1-9, 2018. Disponível em: <http://www.scielo.br/pdf/ean/v22n3/pt_1414-8145-ean-22-03-e20170435.pdf >. Acesso em: 12 de janeiro de 2019.

MARCONI, M. A.; LAKATOS, E. M. Fundamentos de metodologia científica. 7. Ed. São Paulo, SO: Atlas, 2010.

MARIN, M.J.S; GOMES, R; MARVULO, M. M. L; PRIMO, E. M; BARBOSA, P. M. K; DRUZIAN, S. Multiprofessional healthrelated graduate courses: results from experiencesusing active methodologies. Interface - Comuni cação, Saude, Educação, Botucatu, v.14,n.33, p.331-44, abr./jun. 2010. Disponível em: <http://www.scielo.br/scielo.php?script=sci_arttext\&pid=S1414-32832010000200008>. Acesso em: 05 de julho de 2019.

MARTINS, L. M; RIBEIRO, J. L. D. Engajamento do estudante no ensino superior como indicador de avaliação. Avaliação, Campinas; Sorocaba, v. 22, n. 1, p. 223-247, mar. 2017. Disponível em: <http://www.scielo.br/scielo.php?pid=S1414-40772017000100223\&script=sci_abstract\&tlng=pt>. Acesso em: 07 de março de 2019.

MENDES, A. A; VENTURA, R. C. M. O; SOUZA, R. A; MIRANDA, N. T. P; ARAUJO, G. L; ARAKAKI,F. F. S. A percepção dos estudantes do curso de Administração a respeito do processo de implantação de metodologias ativas de ensino aprendizagem - o desenvolvimento da aprendizagem significativa. Pensar Acadêmi co, Manhuaçu, v. 15, n. 2, p. 182192, jul./dez. 2017. Disponível em:

$<$ http://pensaracademico.facig.edu.br/index.php/pensaracademico/article/view/356>. Acesso em: 12 de dezembro de 2018.

OLIVEIRA, G. K. S.; RODRIGUES, K. C.; FREITAS, M. A. O. Concepções de docentes sobre o uso de metodologias ativas da aprendizagem: um enfoque na formação de enfermeiros. Sustinere, Rio de Janeiro, v.6, n. 2, p. 281-299, jul/dez. 2018. Disponível em:<https://www.e-publicacoes.uerj.br/index.php/sustinere/article/view/36366>. Acesso em 18 de fevereiro de 2019.

OLIVEIRA, K. R. E; BRAGA, E. M. O desenvolvimento das habilidades comunicativas e a atuação do professor na perspectiva do aluno de enfermagem. Revista da Escola de Enfermagem da USP, São Paulo, v. 50, n. (esp), p. 32-38, 2016. Disponível em: <http://www.scielo.br/pdf/reeusp/v50nspe/pt_0080-6234-reeusp-50-esp-0032.pdf>. Acesso em: 25 de novembro de 2018.

PARANHOS, V.D; MENDES, M. M. R. Currículo por competência e metodologiaativa: percepção de estudantes de enfermagem. Revi sta Latino Ameri cana de Enfermagem, Ribeirão Preto, v. 18, n.1,jan./ fev. 2010. Disponível em: 
$<$ http://www.scielo.br/scielo.php?pid=S0104-11692010000100017\&script=sci_abstract\&tlng=pt>. Acesso em: $15 \mathrm{de}$ outubro de 2018.

PRADO, C.C; TEOTÔNIO, W. S. Uso de metodologia ativa no ensino do comportamento animal, no curso de psicologia. Revista Thema, Pelotas, v. 17, n. 1, p. 35-44,2020. Disponível em:

http://periodicos.ifsul.edu.br/index.php/thema/article/view/1034. Acesso em: 15 de agosto de 2020.

RAMOS, F. P. A relação professor/ aluno e a prática docente contemporânea. Um ensaio sobre significados a partir da análise de um episódio dos Simpsons. Revista de Educação, v.14, n.17, p. 177-186, 2011. Disponível em: http://revista.pgsskroton.com.br/index.php/educ/article/viewFile/1827/1735. Acesso em:09 abr. 2019.

SANTANA, A. M. B; FERREIRA, J. A; NOGUEIRA, M. F; ANDRADE, L. D. F. Relacionamento interpessoal na prática universitária: Desvendando a visão do discente. Ciência,Cuidado e Saúde, Maringá, v. 14, n. 4, p. 1513-1519, out./dez.2015. Disponívelem:

$<$ http://www.periodicos.uem.br/ojs/index.php/CiencCuidSaude/article/view/29886>. Acesso em:02 e3 fevereiro de 2019.

SANTOS, C. P; SOARES, S. R. Aprendizagem e relação professor-aluno na universidade: duas faces da mesma moeda. Estudos em Avaliação Educacional, São Paulo, v. 22, n. 49, p. 353-370, mai./ago. 2011. Disponível em: <http://www.fcc.org.br/pesquisa/publicacoes/eae/arquivos/1641/1641.pdf>. Acesso em: 13 de dezembro de 2018.

SANTOS, J. C. R; ROCHA, K. M; BARONEZA, A. M; FERNANDES, D. R; SOUZA, V. V; BARONEZA, J. E. Metodologias ativas e interdisciplinaridade na formação do Nutricionista. Semina: Ciências Sociais e Humanas, Londrina, v. 38, n. 1, p. 117-128, jan./jun. 2017. Disponível em:

<http://www.uel.br/revistas/uel/index.php/seminasoc/article/view/28205>. Acesso em: 21 de janeiro de 2019.

SILVA, J. O. M; PEREIRA JUNIOR, G. A; COELHO, I. C. M. M; PICHARSKI, G. L; ZAGONEL, I. P. S. Engajamento entre Estudantes do Ensino Superior nas Ciências da Saúde (Validação do Questionário Ultrecht Work Engagement Scale (UWES-S) com Estudantes do Ensino Superior nas Ciências da Saúde). Revista Brasi leira de Educação Médica, Brasília, v. 42, n.2, p. 14-25, 2018. Disponível em: $<$ http://www.scielo.br/scielo.php?script=sci_abstract\&pid=S010055022018000200015\&lng=en\&nrm=iso\&tlng=pt $>$. Acesso em 01 de março de 2019.

SILVA, L. A. A; SOLDER, R. M; SCHIMDT, S. M; NOAL, H. C; ARB OIT, E. L; MARCO, MARCOS, V. R. Arquétipos docentes: percepções de discentes de Enfermagem. Texto Contexto Enfermagem, Santa Catarina, v. 25, n. 2, p. 1-8, 2016. Disponível em:<http://www.scielo.br/scielo.php?script=sci_abstract\&pid=S010407072016000200316\&lng=en\&nrm=iso\&tlng=pt $>$. Acesso em: 27 de janeiro de 2019.

SOUZA, M. N. C; CRUZ, A. A; SANTOS, Z. M. S. A; CÂNDIDO, A. L. Conhecimento de discentes sobre metodologia ativa na construção do processo de ensino aprendizagem inovador. Revista Interdisciplinar Encontro das Ciências, Icó, v. 1, n.1, p. 61 - 74,2018. Disponível em: 〈http://fvs.edu.br/riec/riec/article/view/7>. Acesso em:21 de março de 2019.

VITORIA, M. I. C; CASARTELLI, A; RIGO, R. M; COSTA, P. T. Engajamento acadêmico: desafios para a permanência do estudante na Educação Superior. Educação, Porto Alegre, v. 41, n. 2, p. 262-269, mai./ago. 2018. Disponível em: $<\underline{\text { https://www.researchgate.net/publication/327711822_Engajamento_academico_desafios_para_a_permanencia_d }}$ o_estudante_na_Educacao_Superior>. Acesso em: 02 de abril de 2019.

WEBER, L. C. Metodologias ativas no processo de ensino da enfermagem: revisão integrativa. $2018.32 \mathrm{f}$. Dissertação (Mestrado em Ensino) - Universidade do Vale do Taquari, Univates. Lajeado. 2018. Disponível em: https://www.univates.br/bdu/bitstream/10737/2494/1/2018LidiaCatarinaWeber.pdf. Acesso em: 20 de julho de 2020.

XAVIER, A. E. O; XAVIER, M. A. S; SAMPAIO, C. A; VELOSO, M. V; SOUTO, I. V; ROYO, V. A; BARRETO, N. A. P. Percepção de estudantes de um mestrado em biotecnologia quanto à aprendizagem baseada em problemas. RevistaUnimontes Científica, Montes Claros, v. 18, n.1, jan./jun. 2016. Disponível em: <http://www.ruc.unimontes.br/index.php/unicientifica/article/view/478>. Acesso em: 12 de março de 2019.

(c) EY

Este trabalho está licenciado com uma Licença Creative Commons - Atribuição 4.0 Internacional. 